\title{
Revision of Amygdalodon patagonicus Cabrera, 1947 (Dinosauria, Sauropoda)
}

\author{
Oliver W. M. Rauhut ${ }^{1}$
}

With 3 figures

\begin{abstract}
The type material of the oldest known sauropod dinosaur from South America, Amygdalodon patagonicus, from the Cerro Carnerero Formation (Toarcian-Bajocian) of Chubut province, Argentina, is reviewed. The material includes elements of at least two individuals plus a remain of another, indeterminate vertebrate, and a posterior dorsal vertebra is designated as the lectotype of Amygdalodon. All of the sauropod material originally referred to this species represents very basal, non-neosauropodan eusauropods. Amygdalodon is the only South American evidence for a probable Early to early Middle Jurassic global dispersal of basal eusauropodan sauropods.
\end{abstract}

Key words: Dinosauria, Sauropoda, Early to Middle Jurassic, Argentina.

\section{Zusammenfassung}

Das Typusmaterial des ältesten südamerikanische sauropoden Dinosauriers, Amygdalodon patagonicus von der Cerro Carnerero Formation (Toarc-Bajoc) der Provinz Chubut, Argentinien, wird revidiert. Das Material enthält Elemente von mindestens zwei Individuen sowie eines anderen, nicht identifizierbaren Wirbeltieres. Ein hinterer Dorsalwirbel wird als Lektotypus von Amygdalodon bestimmt. Das gesamte ursprünglich zu diesem Taxon gestellte Sauropodenmaterial repräsentiert sehr basale Eusauropoden außerhalb der Neosauropoda. Amygdalodon ist der einzige südamerikanische Hinweis auf eine vermutlich globale Verbreitung der Eusauropoden im unteren bis frühen mittleren Jura.

Schlüsselwörter: Dinosauria, Sauropoda, Unterer bis Mittlerer Jura, Argentinien.

\section{Introduction}

In 1947, Cabrera named some fragmentary remains from Jurassic strata in the province of Chubut, Argentina, as a new sauropod taxon, Amygdalodon patagonicus. The material came from the Cerro Carnerero Formation at Pampa de Agnia and represented the first dinosaur described from the Jurassic of South America and one of the oldest sauropod occurrences then known. Casamiquela (1963) redescribed all the original material and referred several other elements in the collections of the Museo de La Plata, Argentina, to the same taxon. The latter material had been collected by the geologist A. Piatnitzky prior to the holotype, apparently from the same locality, and Casamiquela argued that it probably represents the same individual.
Despite its potential importance as South America's oldest known sauropod, Amygdalodon has received surprisingly little attention in the literature, possibly due to the fragmentary nature of the material. Since Casamiquela's redescription of the taxon, it was only mentioned in some rather general overview articles of South American vertebrates or dinosaurs (e.g. Bonaparte $1978,1981,1996$, Novas 1997) or sauropods in general (e.g. McIntosh 1990a). Amygdalodon has generally been regarded as a member of the Cetiosauridae (Cabrera 1947, Casamiquela 1963, Bonaparte 1978, McIntosh 1990a), an assemblage of basal sauropods that is now considered to be paraphyletic (Upchurch 1995, 1998, Wilson 2002). Although listed in his work as a valid taxon, McIntosh (1990a) also indirectly doubted its validity, stating that the elements "indicate cetio-

\footnotetext{
1 Institut für Paläontologie, Museum für Naturkunde, Invalidenstraße 43, 10115 Berlin, Germany, and Museo Paleontológico Egidio Feruglio, Fontana 140, 9100 Trelew, Argentina. Received May, accepted July 2003
} 
saurid affinities but do not serve to clearly differentiate this animal from the other members of this family" (p. 378).

The age of the material is still uncertain. Although usually cited as Bajocian (e.g. McIntosh 1990a, Novas 1997), it has also been regarded as Early Jurassic by some authors (e.g. Bonaparte 1981). The Cerro Carnerero Formation, which yielded the material, is the basal formation of the Lonco Trapial Group and unconformably overlies marine units of early Toarcian age (Riccardi et al. 1992). It is overlain by the Lonco Trapial (= Cañadón Puelman) Formation, a unit of mainly volcanic and volcanoclastic rocks. The age of the Lonco Trapial Group is generally considered to be Toarcian to Middle Jurassic (probably Bathonian in the area concerned; Riccardi et al. 1992, Figari \& Courtade 1993). Page et al. (1999: 466) noted that the volcanism in this area started in the Aalenian, so a late Toarcian to Aalenian age seems to be most likely for the Cerro Carnerero Formation, but more data is needed to confirm this.

The purpose of the present paper is to review the original holotype and referred material of Amygdalodon patagonicus and to evaluate its systematic position on the basis of modern ideas of sauropod phylogeny (Upchurch 1995, 1998, Wilson \& Sereno 1998, Wilson 2002).

Institutional abbreviation: MLP, Museo de La Plata, La Plata, Argentina.

\section{The material of Amygdalodon}

The material referred to Amygdalodon is very fragmentary. Cabreras' (1947) original material (MLP 46-VIII-21-1) consisted of several teeth, a cervical, two dorsal and two caudal vertebral centra and some vertebral fragments, several fragmentary ribs, a partial right pubis, and a plate-like bone that Cabrera identified as a fragment of the scapula (Figs 1, 2). Casamiquela (1963) referred another dorsal vertebra, a sacral vertebral centrum, and a distal end of a tibia, apparently from the same locality as the type, to this taxon (MLP 36-XI-10-3; Fig. 3). For measurements of the elements see Casamiquela (1963).
In the following descriptions, the terminology of the vertebral laminae follows that of Wilson (1999), and that of the lateral vertebral recesses that of Makovicky (1997).

\section{The type material}

Te e th: Of the originally four complete and three fragmentary teeth of Amygdalodon, only one almost complete element could be located in the collections of the La Plata Museum (Fig. 1A, B). It has an asymmetrical spatulate crown with a well-developed wear-facet on the distal carina apically, which is more strongly developed laterally than lingually. No marginal denticles are present on the anterior carina up to where it meets the posterior wear-facet. Well-developed longitudinal grooves parallel to the carina are present lingually and laterally along the anterior carina and at least laterally along the posterior carina. Apart from the marginal groove, the lingual side of the crown is slightly convex mesio-distally, as in Cardiodon (Upchurch \& Martin 2003). The root is considerably longer and mesio-distally narrower than the crown and approximately round in cross-section.

Cervical vertebrae: Only the body of an anterior cervical vertebra and an isolated prezygapophysis of a more posterior cervical are present.

The preserved centrum represents an anterior or middle cervical (Fig. 1C-E). The centrum is opisthocoelous, elongate and very strongly flexed ventrally in its anterior part, so that the anterior articular surface is strongly offset from the posterior. The parapophyses are elongate, oval in shape and placed on the anteroventral edge of the centrum. A small ridge runs from the posterior end of the parapophysis posteriorly along the ventral edge of the lateral side and disappears at approximately half the length of the centrum. A pleurocoel is absent; only a large, very shallow depression is present on the sides and is deeper anteriorly than posteriorly. Likewise, no excavations are present on the dorsal surfaces of the parapophyses. In ventral view, the centrum is strongly constricted behind the parapophyses and has a well-developed, sharp ventral keel in its flattened anterior half. The posterior half of

Fig. 1. Type material of Amygdalodon patagonicus Cabrera, 1947. A. B. Tooth, MLP 46-VIII-21-1/13, in lingual (A) and labial (B) view. C, D, E. Cervical vertebra, MLP 46-VIII-21-1/8, in right lateral (C, stereopair), ventral (D) and left lateral (E) view. F, G. Right cervical prezygapophysis, MLP 46-VIII-21-1/7, in dorsal (F) and medial (G) view. H. Anterior dorsal neural spine, MLP 46-VIII-21-1/6, in posterior view. I, J, K. Posterior dorsal vertebra, MLP 46-VIII-21-1/2, lectotype, in right lateral view 


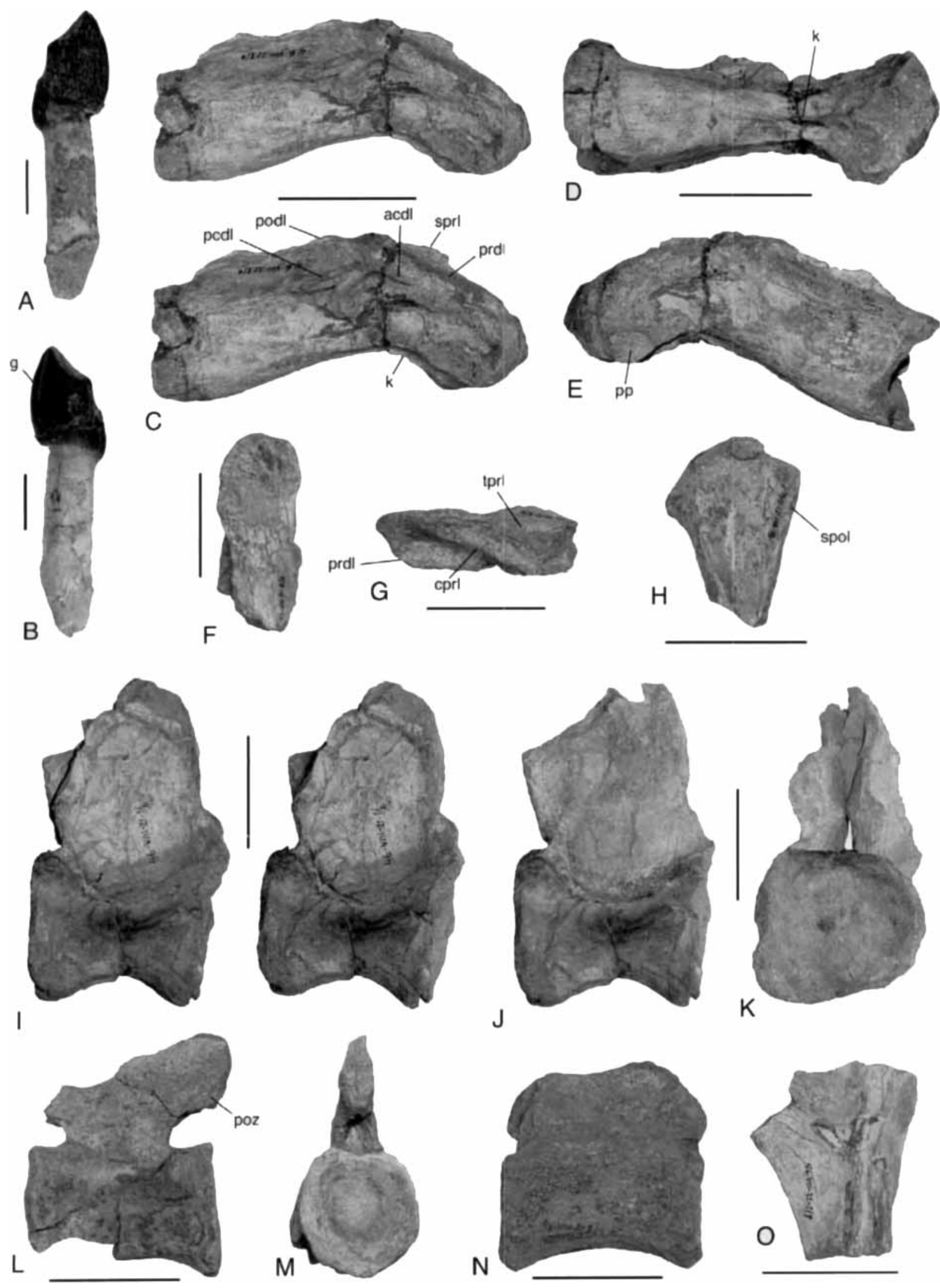

(I, stereopair), right lateral view, with right wall of neural canal remived (J), and posterior (K) view. L, M. Caudal vertebra, MLP 46-VIII-21-1/3, in left lateral (L) and posterior (M) view. N. Caudal vertebra, MLP 46-VIII-21-1/4, in right lateral view. o. Proximal fragment of a dorsal rib, MLP 46-VIII-21-1/9, in anterolateral view. Abbreviations: acdl, anterior centrodiapophyseal lamina; cprl, centroprezygapophyseal lamina; g, groove; k, ventral keel; pcdl, posterior centrodiapophyseal lamina; podl, postzygodiapophyseal lamina; poz, postzygapophysis; pp, parapophysis; prdl, prezygodiapophyseal lamina; spol, spinopostzgapophyseal lamina; sprl, spinoprezygapophyseal lamina; tprl, intraprezygapophyseal lamina. Scale bars $1 \mathrm{~cm}(\mathrm{~A}, \mathrm{~B})$ and $10 \mathrm{~cm}$ $(\mathrm{C}-\mathrm{O})$. 
the ventral side is transversely rounded and without a keel.

Only the bases of the neural arch with the neural canal is present. The latter is collapsed, so that not much can be said about its shape, but it seems to have been relatively small in comparison with the vertebral centrum. Most of the vertebral laminae are broken off and only the bases of some are visible, better preserved on the right than on the left side. The anterior centrodiapophyseal lamina is slender and short and does not reach the anterior end of the centrum. It is more anteriorly than ventrally directed. The posterior centrodiapophyseal lamina is considerably more stout and longer and its orientation is subhorizontal. The broken prezygodiapophyseal lamina was rather stout and met the diapophysis slightly above the anterior centrodiapophyseal lamina. Likewise, the postzygodiapophyseal lamina extends from posterodorsal anteroventrally and is placed considerably above the posterior centrodiapophyseal lamina, so that the infrapostzygapophyseal recess was very large and opened mainly posteriorly. Anteriorly, the broken basis of the stout spinoprezygapophyseal lamina is present mediodorsally to the prezygodiapophyseal lamina.

A large right prezygapophysis represents a posterior cervical vertebra (Fig. 1F, G). The articular surface is obliquely oval in shape (max. $69 \mathrm{~mm}$ wide and $74 \mathrm{~mm}$ long) and has a shorter, almost straight lateral margin and a longer, convex anteromedial margin. The vertebral laminae are well developed. The prezygodiapophyseal lamina is the most robust and extends furthest anteriorly on the ventral side of the prezygapophysis. The centroprezygapophyseal lamina is positioned more medially on the underside of the prezygapophysis and extends posteroventrally, so that its ventral margin is below the posterior end of the articular surface at the ventral break, indicating that the prezygapophyses overhang the vertebral centrum anteriorly. The orientation of this lamina also indicates that the prezygapophysis was considerably inclined medially. Dorsomedially to the centroprezygapophyseal lamina, the remains of another, very slender lamina are visible, probably the intraprezygapophyseal lamina.

Dorsal vertebrae: The type material includes the tip of an anterior dorsal neural spine and two posterior dorsal vertebral centra.

The dorsal neural spine was misidentified as a caudal spine by Cabrera (1947) and as a dorsal diapophysis by Casamiquela (1963). However, its shape in combination with the presence of spinoprezygapophyseal and spinopostzygapophyseal laminae clearly indicate that it is one of the anteriormost dorsal neural spines (Fig. 1H). The spine is strongly flattened anteroposteriorly and transversely expanded dorsally, although this expansion terminates a short way below the distal end, above which the tip of the spine is broadly rounded. A small anterior and posterior projection is present at the distalmost tip of the spine, probably for the attachment of an interspinal ligament. Both the spinoprezygapophyseal and spinopostzygapophyseal laminae extend along the lateral margin of the anterior and posterior side of the spine, respectively. Whereas the spinoprezygapophyseal laminae are only represented by slightly elevated ridges, the spinopostzygapophyseal laminae were obviously stout and extended from the distal part of the spine posteroventrally, but are largely broken off.

Only the centra and the rim of the neural canal of the dorsal vertebrae are preserved (Fig. 1I-K). No parapophyses or spinal laminae are present on the preserved parts, indicating that the two elements are posterior dorsal vertebrae. Both elements are of very similar dimensions, with centrum lengths of 138 and $131 \mathrm{~mm}$, respectively. The vertebral centra are massive, approximately as high as long, with a very broad ventral part. Pleurocoels are absent, but large pleurocentral depressions are present on the dorsal part of the lateral sides, so that the centra are pear-shaped in cross-section (see Cabrera 1947: fig. $3 \mathrm{C}$ ). The neural arches are at least as high as the centra. The neurocentral suture is visible and lies above the neural canal, so that the lateral borders of the latter are formed by pedicles of the centrum, as in some other sauropods (McIntosh 1990b). The neural canal is high slit-like and narrows dorsally. In one of the vertebrae, the right wall of the neural canal is broken and can be removed, revealing that the canal was strongly convex ventrally as seen in lateral view inside the vertebra. The anterior side above the neural canal is flat, without a marked depression, but with a small vertical ridge that is slightly displaced laterally from the midline. Posteriorly, the walls of the neural canal flare outwards, both at the exit of the canal as well as above it.

Caudal vertebrae: Two mid-caudal vertebrae of very similar dimensions are present, one of them with parts of the neural spine preserved (Fig. 1L-N). The centra are elongate spool- 
shaped and oval in cross-section, being slightly higher than wide. The more anterior element (Fig. 1L, M) has small, ridge-like transverse processes preserved. In this vertebra, the neural arch is placed on the middle of the centrum, slightly more off set from the posterior than the anterior end. The neural canal is a high oval in shape. The broken prezygapophyses were placed on short, stout anterior processes, whereas the postzygapophyses are found on the ventrolateral side of the neural spine, just where it overhangs the posterior end of the centrum. The neural spine itself arises from the posterior two thirds of the neural arch and is slightly more strongly posteriorly than dorsally directed; its distal end is broken.

The other vertebra is very poorly preserved (Fig. 1N). It lacks transverse processes and the centrum is slightly more elongate, indicating that it is a more distal element than the former. Chevron facets are only weakly developed. The neural arch seems to extend over the entire length of the centrum, though some uncertainty about this remains due to the poor preservation.

Ribs: The ribs are very fragmentary. They were double-headed with a well-developed, plate-like web between capitulum and tuberculum present in some elements (Fig. 1O). No pneumatic depressions, foramina, or internal spaces are present.

Pubis: Only the shaft and distal end of a rather massive right pubis are preserved (Fig. 2A, B). The shaft is broader transversely than anteroposteriorly and tear-shaped in cross-section, with its lateral edge the widest and the medial side confluently fading into the plate-like pubic apron. The distal end is considerably expanded, both laterally and antero-posteriorly, with a wellrounded distal extreme. Unlike the situation in the "pubic boot" of theropod dinosaurs, the distal expansion gradually fades into the shaft. Distally, the pubes were separated; the pubic apron begins some $110 \mathrm{~mm}$ proximal to the distal end.

Plate-like bone: An unusual, rectangular, plate-like bone was regarded as part of the scapula by Cabrera (1947), while Casamiquela (1963) interpreted it as a "horizontal lamina of a dorsal vertebra". The element, as preserved, seems almost quadrangular, but only two of the margins are original and meet each other at a right angle, whereas the opposite two sides are broken (Fig. 2C, D). One side of the bone (?the external) is convex in all direction, while the other side is slightly concave. On the concave side, a broken attachment of a slender bone is fused to the element approximately in its middle and fades into the plate-like element towards the opposite side of the corner formed by the two original margins (Fig. 2D).

\section{Referred material}

Dorsal vertebra: Apart from a slight deformation that makes the element appear slightly more slender and higher, this vertebra is so similar in morphology and dimensions to the dorsals of the type material that no further description is necessary (Fig. 3A). As noted by Casamiquela
A

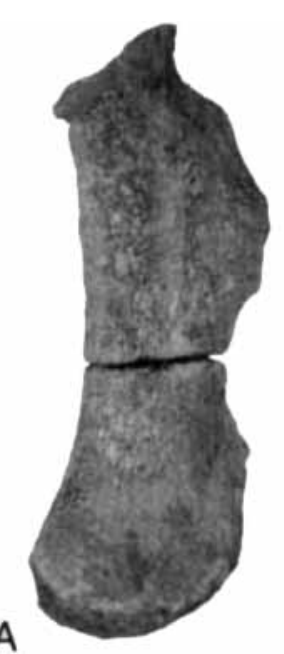

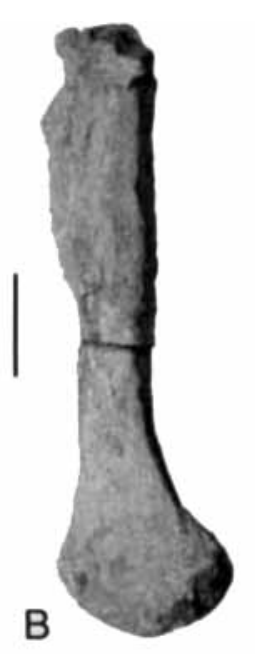

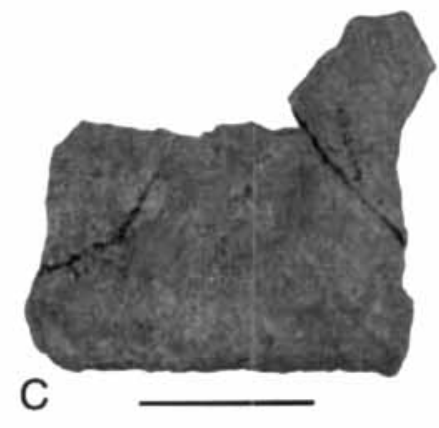

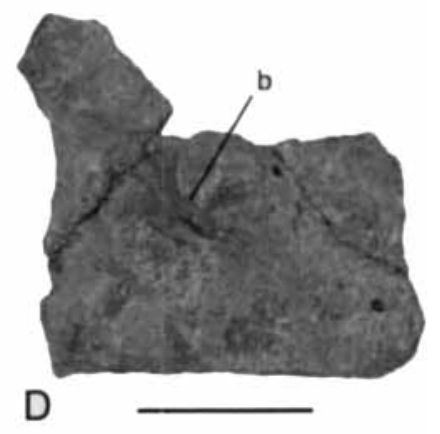

Fig. 2. Type material of Amygdalodon patagonicus Cabrera, 1947. A, B. Right pubis, MLP 46-VIII-21-1/19, in anterior view, slightly turned medially (A) and lateral view (B). C, D. Plate-like bone, MLP 46-VIII-21-1/10, in ?external (C) and ?internal (D) view. Abbreviations: $\mathbf{b}$, rod-like bone fused to internal surface of the plate-like bone. Scale bars are $10 \mathrm{~cm}$. 
(1963) it might well represent a single series of subsequent vertebrae together with the latter, although its exact position in respect to them is uncertain due to the lack of most of the neural arches in all elements. Interestingly, a fragment of a double-headed rib is attached to the left side of the neural arch of this vertebra (Fig. 3A). The rib has a bony web between tuberculum and capitulum similar to the ribs of the type material, but is considerably smaller than some of the rib heads included in the latter.

Sacral vertebra: Only half of a sacral centrum is preserved (Fig. 3B, C). This element was identified as a caudal vertebra by Casamiquela (1963), but its morphology is more consistent with sacral vertebrae. The element probably represents the first sacral, as judged by the large and strongly expanded anterior articular surface. The articular surface is almost round in crosssection and slightly broader than high. The cen- trum is strongly constricted behind the anterior end and was obviously much shorter than high. A large, plate-like transverse process extends from the mid-height of the anterior end of the centrum dorsally and slightly posteriorly; this process is not supported by any additional lamina arising from the vertebral body or the preserved parts of the neural canal. Behind the process, a large, round foramen is present in the wall of the neural canal, probably an exit of a spinal nerve.

Tibia: The right tibia is represented by its distal end (Fig. 3D-F). The shaft is robust and distally it is only posteriorly expanded. The distal end is approximately triangular in outline, broad medially and narrowing laterally. Laterally, the articular surface is considerably raised proximally, to allow the ascending process of the astragalus to key into the tibia. The posteroventral process of the tibia is reduced laterally.

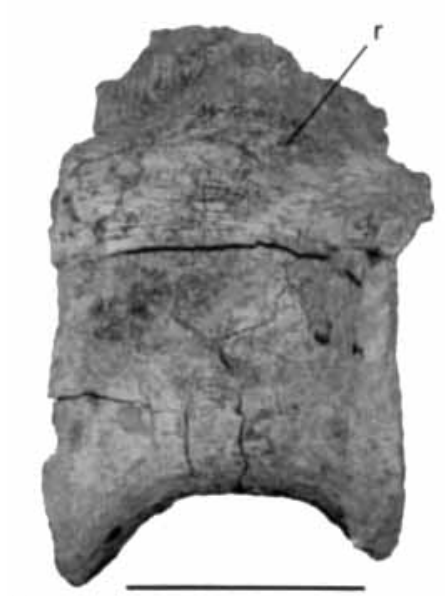

A

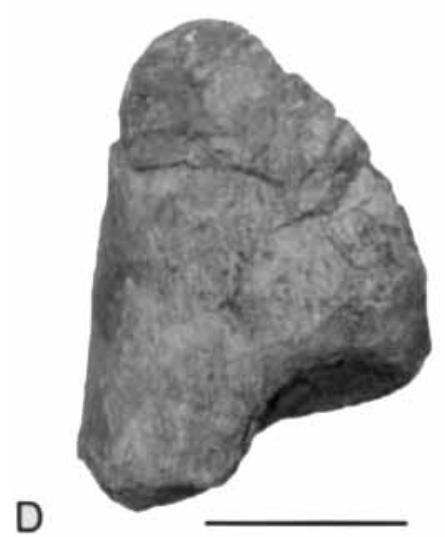

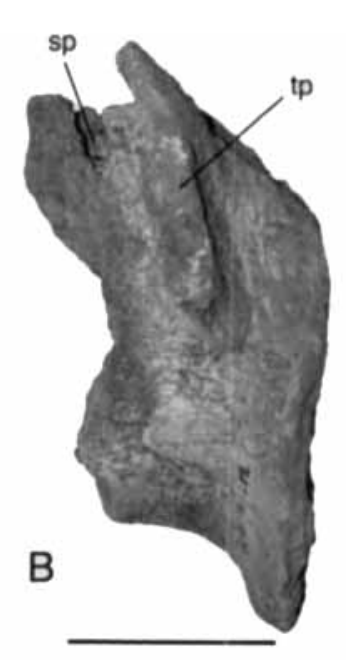
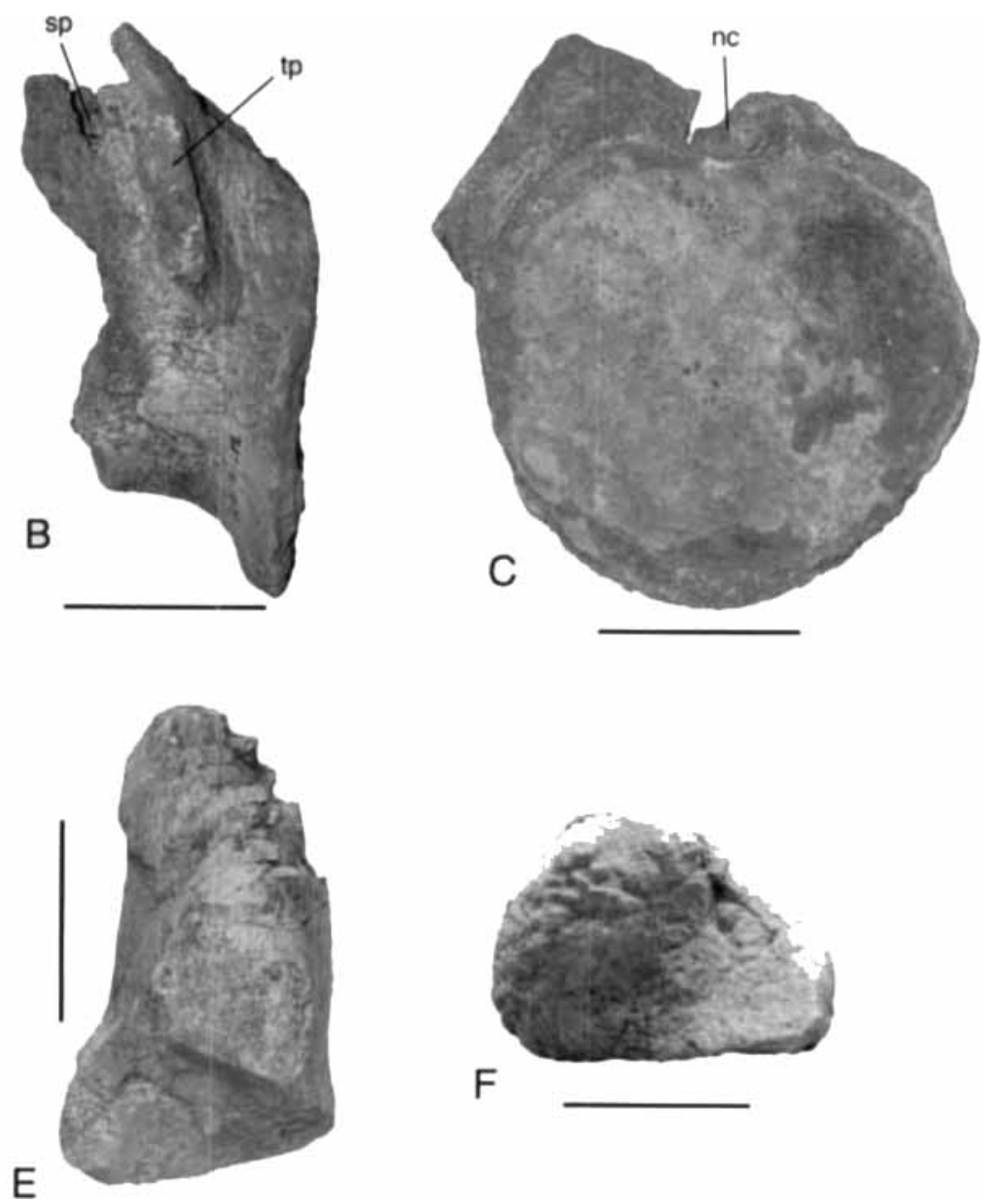

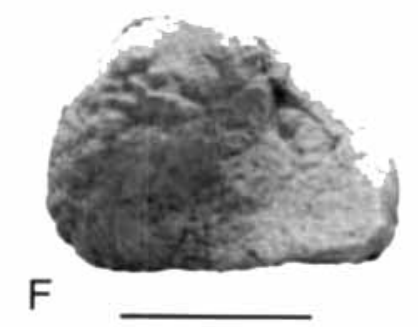

Fig. 3. Material referred to Amygdalodon patagonicus Cabrera, 1947, by Casamiquela (1963). A. Posterior dorsal vertebra with attached proximal fragment of a dorsal rib, MLP 36-XI-10-3/1, in left lateral view. B, C. First sacral vertebra, MLP 36-XI10-3/2, in right lateral (B) and anterior (C) views. D, E. F. Distal end of right tibia, MLP 36-XI-10-3/4, in posterior (D), lateral (E) and distal (F) view. Abbreviations: nc, neural canal; r, rib; sp, foramen for the exit of a spinal nerve; tp, transverse process. Scale bars $10 \mathrm{~cm}$. 


\section{Discussion}

Unfortunately, no information exists about the association of either the type or the referred material of Amygdalodon in the field. However, given the fact that both materials were collected by geologists working for oil companies (Cabrera 1947, Casamiquela 1963) it seems likely that the material was collected from the surface. This is supported by the fact that the material was obviously collected at the same spot by two different geologists some ten years apart (Casamiquela 1963). Thus, there is no direct evidence that all of it represents a single individual. However, several aspects indicate that actually more than one animal is represented.

The most obvious evidence is the size difference between the dorsal vertebrae and the referred sacral vertebra. Since the dorsal vertebrae are posterior dorsals, as indicated by the lack of parapophyses and lateral vertebral laminae on the preserved parts of the neural arch, their centrum height and width should approximately match that of the first sacral centrum. However, the centrum height of the larger dorsal of the type $(138 \mathrm{~mm})$ is only $70 \%$ that of the sacral vertebra $(197 \mathrm{~mm})$. Likewise, the size difference between the rib-head attached to the referred dorsal and some of the rib fragments included in the type also indicate that at least two animals of different sizes are represented. Within the type material, the isolated cervical prezygapophysis also seems to big to go with the dorsal vertebrae, with a maximal width of the articular surface $(69 \mathrm{~mm})$ that exceeds half the anterior width of the centra of the latter (c. $130 \mathrm{~mm}$ ). Finally, the plate-like bone included in the type does not match any sauropod skeletal element and thus indicates the presence of a different clade, although it can presently only be regarded as Vertebrata indet.

Thus, this obvious inclusion of different animals in the type and referred material of Amygdalodon patagonicus makes a designation of a lectotype for this species necessary.

\section{Systematic Palaeontology}

Dinosauria Owen, 1842

Saurischia Seeley, 1887

Sauropodomorpha von Huene, 1932

Sauropoda Marsh, 1878

Eusauropoda Upchurch, 1995 (sensu Wilson \& Sereno 1998)

\section{Amygdalodon Cabrera, 1947}

Type and only known species: Amygdalodon patagonicus Cabrera, 1947.

Diagnosis: As for A. patagonicus (see below).

\section{Amygdalodon patagonicus Cabrera, 1947}

Figs 1I-K, 3A

Lect oty pe: MLP 46-VIII-21-1/2, posterior dorsal vertebra (Fig. 1I-K).

Referred material: MLP 46-VIII-21-1/1, MLP 36-XI-10-3/1 posterior dorsal vertebrae, with an attached head of a dorsal rib.

Revised diagnosis: Lateral walls of the neural canal and centropostzygapophyseal laminae flared laterally posteriorly; neural canal strongly flexed anteroposteriorly within the dorsal neural arches.

Type locality and horizon: Cañadón Puelman, Pampa de Agnia, Chubut, Argentina. According to Casamiquela (1963) the material came from a section of some $100 \mathrm{~m}$ of sandstones and tuffs. The section is now considered to belong to the Cerro Carnerero Formation, Toarcian to Bajocian (Riccardi \& Damborenea 1993).

Discussion: The posterior dorsal vertebra MLP 46-VIII-21-1/2 (Fig. 1I-K) is chosen as lectotype here, since this element shows some diagnostic characters and allows a confident referral of at least the other two posterior dorsals to the same taxon on the basis of the apomorphic character of the posteriorly flared walls of the neural canal. As noted above, all these dorsals might well represent a single individual, but this remains beyond proof. It should be noted, though, that it also remains very possible that all the material, with the exception of the plate-like bone, represents at least two individuals of a single taxon, Amygdalodon patagonicus. However, this can only be demonstrated by the discovery of more complete material of this taxon. In case all the material represents a single taxon, further diagnostic characters of Amygdalodon might include the very pronounced flexure of the cervical centrum and the webbing between the heads of the dorsal ribs.

\section{Phylogenetic considerations}

Although statements on the phylogenetic position of Amygdalodon and the other sauropod material from the Cerro Carnerero Formation 
are limited by the fragmentary nature of the material available, recent phylogenetic analyses of sauropod dinosaurs (Upchurch 1998, Wilson \& Sereno 1998, Wilson 2002) provide a wealth of character information (and a phylogenetic framework to evaluate further characters) to at least narrow down the phylogenetic position of this material.

The lectotype and referred specimens of Amygdalodon can be shown to belong to the Eusauropoda (sensu Wilson \& Sereno 1998) on the basis of the height of the dorsal neural arches being equal to or exceeding the height of the centrum (Bonaparte 1986, Upchurch 1998). Within Eusauropoda, Amygdalodon lacks any synapomorphies of any higher clades, such as a deep excavation of the cranial surface of the dorsal neural arches (Upchurch 1998), or internal cavities above the neural canal (Upchurch 1998), and deep excavations on the neural arches of the dorsal vertebrae below the transverse processes (Upchurch 1998). Since two of these characters are synapomorphies of Eusauropoda in Upchurch's (1998) analysis (if the definition of this clade given by Wilson \& Sereno 1998, is applied to his cladogram; Upchurch actually used the name Eusauropoda at a higher node), their absence in Amygdalodon indicates that the latter is one of the most basal eusauropods known.

Likewise, several of the other sauropod elements originally included in Amygdalodon can be shown to represent very basal eusauropods. The teeth show the eusauropod synapomorphies of a spatulate crown (Wilson \& Sereno 1998, Wilson 2002), wrinkled enamel (Wilson \& Sereno 1998, Wilson 2002), presence of V-shaped wear-facets (Wilson \& Sereno 1998, Wilson 2002), and well-developed grooves on the labial surfaces of the crown paralleling the crown margins (Upchurch 1998), but lacks the eusauropod synapomorphy of the lingual side of the tooth being concave (Upchurch 1998). The cervical vertebra can be referred to the Eusauropoda on the basis of a strongly opisthocoelous centrum (Upchurch 1998, Wilson \& Sereno 1998, Wilson 2002) and the presence of well-developed centrodiapophyseal laminae (Upchurch 1998), but can be shown to represent a very basal member of this clade by the retention of plesiomorphic characters, such as the neural arch of the cervical vertebra being lower than the posterior articular surface of the centrum (Wilson 2002), the absence of cervical pleurocoels (Upchurch 1998, Wilson \& Sereno 1998, Wilson 2002), and no excavations on the dorsal surfaces of the parapo- physes (Upchurch 1998). Some of the other elements (caudal vertebrae, pubis, tibia) can be shown to represent a sauropod or eusauropod dinosaur, but do not preserve enough characters to clarify their position within these clades.

In summary, all the material for which phylogenetic information is available indicates the presence of at least one taxon of basal eusauropodan sauropod in the Early to early Middle Jurassic of Patagonia. The consistency in the phylogenetic information from the different elements might support the probability that all of the material represents a single taxon. Thus, Amygdalodon might prove to be an important taxon for our understanding of the origin and early evolution of the Sauropoda, once more material is known. Wilson (2002: 248) assumed a slightly more derived phylogenetic position for Amygdalodon, as a member of a clade including Patagosaurus and more derived sauropods, on the basis of the cervical ribs being positioned ventrolateral to the centrum. However, apart from the character evidence in favour for a more basal position for the cervical vertebra listed above, no cervical rib is preserved in articulation with the centrum and the slight ventrolateral orientation of the parapophysis of the cervical vertebra might well be an artifact of preservation.

The history of sauropod dinosaurs reaches back to at least the Late Triassic (Buffetaut et al. 2000) and already this oldest known sauropod, Isanosaurus, seems to be a member of the Eusauropoda (Wilson 2002). In the Early Jurassic, eusauropod dinosaurs have been reported from India (Jain et al. 1975, Yadagiri 2001) and Asia (Barrett 1999, see also Wilson 2002). The late Early Jurassic European sauropod, Ohmdenosaurus, probably also belongs to this clade, as indicated by the reduction of the distal posteroventral process of the tibia (Wild 1978). Amygdalodon extends the Jurassic eusauropod record to the early Middle or even Early Jurassic of South America, indicating that this clade had achieved a wide, probably global distribution by the early Middle Jurassic.

\section{Acknowledgements}

Special thanks are due to Marcelo Reguero for access to the material and assistance during my stay in the Museo de La Plata. Zulma Gasparini kindly provided information on the stratigraphic provenance of the material. The manuscript benefited from critical reviews by Kristi Curry-Rogers, WolfDieter Heinrich, Paul Upchurch, and Gloria Arratia. This research was supported by a grant from BBC/Horizon and a fellowship from the DAAD. The author is currently supported by the DFG under project RA 1012/1-1. 


\section{References}

Barrett, P. M. 1999. A sauropod dinosaur from the Lower Lufeng Formation (Lower Jurassic) of Yunnan Province, People's Republic of China. - Journal of Vertebrate Paleontology 19 (4): 785-787.

Bonaparte, J. F. 1978. El Mesozoico de América del Sur y sus tetrápodos. - Opera Lilloana 26: 1-596.

- 1981. Inventario de los vertebrados Jurásicos de América del Sur. In Volkheimer, W. \& Musacchio, E. A. (eds). Cuencas Sedimentarias del Jurásico y Cretácico de América del Sur, Volumen 2: 661-684, Comité Sudamericano del Jurásico y Cretácico, Buenos Aires.

- 1986. The early radiation and phylogenetic relationships of the Jurassic sauropod dinosaurs, based on vertebral anatomy. In Padian, K. (ed.). The Beginning of the Age of Dinosaurs: 245-258, Cambridge University Press, Cambridge.

- 1996. Dinosaurios de América del Sur. 174 pp., Museo Argentino de Ciencias Naturales "Bernardino Rivadavia", Buenos Aires.

Buffetaut, E., Suteethorn, V., Cuny, G., Tong, H., Le Loeuff, J., Khansubha, S. \& Jongautcharlyakul, S. 2000. The earliest known sauropod dinosaur. - Nature 407: 72-74.

Cabrera, A. 1947. Un saurópodo nuevo del Jurásico de Patagonia. - Notas del Museo de La Plata, Paleontología 12 (95): $1-17$

Casamiquela, R. M. 1963. Consideraciones acerca de Amygdalodon Cabrera (Sauropoda, Cetiosauridae) del Jurásico Medio de la Patagonia. - Ameghiniana 3 (3): 79-95.

Figari, E. G. \& Courtade, S. F. 1993. Evolución tectosedimentaria de la Cuenca de Cañadón Asfalto, Chubut, Argentina. - XII Congreso Geológico Argentino y II Congreso de Exploración de Hidrocarburos, Actas 1: 66-77.

Huene, F. von 1932. Die fossile Reptil-Ordnung Saurischia, ihre Entwicklung und Geschichte. - Monographien zur Geologie und Palaeontologie (Serie 1) 4: 1-361.

Jain, S. L., Kutty, T. S., Roy-Chowdhury, T. \& Chatterjee, S. 1975. The sauropod dinosaur from the Lower Jurassic Kota Formation of India. - Proceedings of the Royal Society of London A 188: 221-228.

Makovicky, P. J. 1997. Postcranial axial skeleton, comparative anatomy. In Currie, P. J. \& Padian, K. (eds). Encyclopedia of Dinosaurs: 579-590, Academic Press, San Diego.

Marsh, O. C. 1878. Principal characters of American Jurassic dinosaurs. Part I. - American Journal of Science (ser. 3) 16: $411-416$

McIntosh, J. S. 1990a. Sauropoda. In Weishampel, D. B., Dodson, P. \& Osmólska, H. (eds). The Dinosauria: 345-401, University of California Press, Berkeley.

McIntosh, J. S. 1990b. Species determination in sauropod dinosaurs with tentative suggestions for their classification.
In Carpenter, K. \& Currie, P. I. (eds). Dinosaur systematics. Approaches and perspectives: 53-69, Cambridge University Press, Cambridge.

Novas, F. E. 1997. South American dinosaurs. In Currie, P. J. \& Padian, K. (eds). Encyclopedia of Dinosaurs: 678-689, Academic Press, San Diego.

Owen, R. 1842. Report on British fossil reptiles. Part II. Reports of the British Association for the Advancement of Sciences 11: 60-204.

Page, R., Ardolino, A., de Barrio, R. E., Franchi, M., Lizuain, A., Page, S. \& Nieto, D. S. 1999. Estratigrafía del Jurásico y Cretácico del Macizo de Somún Curá, Provincias de Río Negro y Chubut. In Caminos, R. (ed.). Geología Argentina: 460-488, Subsecretaría de Minería de la Nación, Buenos Aires.

Riccardi, A. C. \& Damborenea, S. E. (eds) 1993. Léxico estratigráfico de la Argentina. Vol. IX. Jurásico. $365 \mathrm{pp}$., Asociácion Geológica Argentina, Buenos Aires.

Riccardi, A. C., Gulisano, C. A., Mojica, J., Palacios, O., Schubert, C. \& Thomson, M. R. A. 1992. Western South America and Antarctica. In Westerman, G. E. G. (ed.). The Jurassic of the Circum-Pacific: 122-161, Cambridge University Press, Cambridge.

Seeley, H. G. 1887. On the classification of the fossil animals commonly named Dinosauria. - Proceedings of the Royal Society of London 43: 165-171.

Upchurch, P. 1995. The evolutionary history of sauropod dinosaurs. - Philosophical Transactions of the Royal Society of London B 349: 365-390.

- 1998. The phylogenetic relationships of sauropod dinosaurs. - Zoological Journal of the Linnean Society 124: 43-103.

Upchurch, P. \& Martin, J. 2003. The anatomy and taxonomy of Cetiosaurus (Saurischia, Sauropoda) from the Middle Jurassic of England. - Journal of Vertebrate Paleontology 23 (1): 208-231.

Wild, R. 1978. Ein Sauropoden-Rest (Reptilia, Saurischia) aus dem Posidonienschiefer (Lias, Toarcium) von Holzmaden. - Stuttgarter Beiträge zur Naturkunde, Serie B 41: $1-15$.

Wilson, J. A. 1999. A nomenclature for vertebral laminae in sauropods and other saurischian dinosaurs. - Journal of Vertebrate Paleontology 19 (4): 639-653.

- 2002. Sauropod dinosaur phylogeny: critique and cladistic analysis. - Zoological Journal of the Linnean Society 136: $217-276$.

Wilson, J. A. \& Sereno, P. C. 1998. Early evolution and higher-level phylogeny of sauropod dinosaurs. - Society of Vertebrate Paleontology, Memoir 5: 1-68.

Yadagiri, P. 2001. The osteology of Kotasaurus yamanpalliensis, a sauropod dinosaur from the Early Jurassic Kota Formation of India. - Journal of Vertebrate Paleontology 21 (2): 242-252. 